\title{
REPRESENTAÇÃO E PRÁTICAS DE UTILIZAÇÃO DE PRODUTOS AGROQUÍMICOS NA PEQUENA AGRICULTURA FAMILIAR DO VALE DO RIBEIRA, ESTADO DE SÃO PAULO, BRASIL
}

Maria Helena Rocha Antuniassi*

Luis Carlos Ferreira de Almeida**

Resumo: Trata-se de um estudo de sociologia realizado no âmbito de um programa de extensão rural desenvolvido no Vale do Ribeira - Estado de São Paulo-(2013/2014) por uma equipe do Centro de Estudos Rurais NAP/USP e da UNESP, Campus Experimental de Registro, tendo por objetivo disseminar junto aos produtores rurais, sobretudo da agricultura familiar, conceitos e práticas relativas à saúde do trabalhador, principalmente a correta utilização do EPI e preservação do meio ambiente (solo e águas) para que suas atividades se efetivem direcionadas para o desenvolvimento sustentado (socioeconômico e ambiental) de seu município e região. Tendo em vista os objetivos estabelecidos, o estudo foi realizado utilizando a observação participante, uma metodologia da pesquisa-ação que busca simultaneamente compreender e intervir; supõe familiaridade anterior com o objeto e tem, portanto, dois objetivos: produção de conhecimentos e mudança das práticas observadas, por meio de uma ação pedagógica, que tem por base não apenas o conhecimento da experiência vivida dos agentes observados, mas as condições sociais de possibilidade dessa experiência (portanto, os efeitos e os limites). (BOURDIEU, 2003). Assim sendo, buscou-se apreender a representação dos agricultores sobre os produtos agroquímicos e sua utilização, tendo em vista a participação de suas associações e serviços de extensão rural nas suas práticas de utilização dos produtos.

Palavras-chave: Agricultura familiar. Agroquímicos. Extensão rural. Pesquisa-ação.

\begin{abstract}
The Centre for Rural and Urban Studies (NAP/USP) and UNESP - Campus Experimental at Registro developed a sociological study as a part of a rural extension program in Vale do Ribeira region, State of São Paulo, Brazil (2013/2014), aiming to spread along to rural producers, particularly from family farming, concepts and practices related to workers' health, especially the correct use of PPE and environment preservation (soil and water) for their activities, in order to take effect directed to sustainable development (social, economic and environmental) of their municipality and region. The study was conducted using participant observation, a methodology of action research that seeks simultaneously to understand and to intervene, assumes familiarity with the object and therefore has two production purposes: production of knowledge and change of practices observed. This is done through a pedagogical action, which is not based only on the knowledge of experience lived by the observed agents but the social conditions to make possible this experience (thus, the effects and limits). (BOURDIEU, 2003). Therefore, it sought to learn the representation of rural producers on agrochemicals and its use, looking at the participation of their associations and rural extension services in their product user practices.
\end{abstract}

Key Words: Family farming. Agrochemical. Rural extension. Action-research.

\footnotetext{
* Centro de Estudos Rurais e Urbanos - NAP/USP. E-mail: mhrochaa@gmail.com.

** Curso de Agronomia - UNESP - Campus Experimental de Registro. E-mail: luiscarlos.almeida@gmail.com.
} 
Este artigo tem por base um estudo sócio-antropológico realizado no âmbito de um programa de extensão rural desenvolvido no alto e baixo Vale do Ribeira - Estado de São Paulo (2013/2014), por uma equipe do Centro de Estudos Rurais e Urbanos (NAP/USP) e a UNESP, Campus Experimental de Registro $^{1}$, tendo por objetivo disseminar junto aos produtores rurais, sobretudo da agricultura familiar, conceitos e práticas relativas à saúde do trabalhador, principalmente quanto à correta utilização do EPI (equipamento de proteção individual) e preservação do meio ambiente (solo e águas) para que as suas atividades se efetivem direcionadas para o desenvolvimento sustentado (socioeconômico e ambiental) de seu município e região.

\section{Metodologia}

Tendo em vista os objetivos estabelecidos, o estudo foi realizado utilizando a observação participante, uma metodologia da pesquisa-ação que busca simultaneamente compreender e intervir; supõe familiaridade anterior com o objeto e tem, portanto, dois objetivos: produção de conhecimentos e mudança das práticas observadas, por meio de uma ação que tem por base não apenas o conhecimento da experiência vivida dos agentes observados, mas também das condições sociais de possibilidade dessa experiência (portanto, os efeitos e os limites) (BOURDIEU, 2003). Assim sendo, buscou-se apreender a representação dos agricultores sobre os produtos agroquímicos e suas práticas de utilização, observando, inclusive, a participação de suas associações e serviços de extensão rural nessas atividades.

\footnotetext{
${ }^{1}$ Os autores agradecem a colaboração do Prof. Dr. François Bonvin - École des Hautes Études, Paris.
} primeira, dedicada à seleção de uma região do Estado de São Paulo em que a agricultura familiar tivesse relevância e com indicações, seja colhida na imprensa ou junto aos agrônomos da CATI (Secretaria de Agricultura do Estado de São Paulo) de que a utilização de agroquímicos fosse feita de maneira constante, com evidências de desconhecimento das corretas práticas de utilização dos respectivos produtos. Seleção e treinamento dos estudantes do curso de Agronomia da Universidade Estadual Paulista - UNESP, Campus Experimental de Registro, que atuaram nos treinamentos ${ }^{2}$; b) Planejamento da metodologia e realização da pesquisa-ação.

\subsection{A regiño: VAle do Ribeira}

Para o desenvolvimento do projeto, foi escolhida a região da Bacia Hidrográfica do Rio Ribeira do Iguape e o Complexo Estuário Lacunar de Iguape-Cananéia-Paranaguá, conhecida como Vale do Ribeira, que abrange as regiões sudeste do Estado de São Paulo e leste do Estado do Paraná e possuindo uma área de 2.830.666 hectares, ou seja, $2.830,7 \mathrm{~km}^{2}$. Abrange um total de trinta e um municípios (nove no Estado do Paraná e vinte e dois no Estado de São Paulo) e uma população de cerca de 484.412 habitantes, localizando-se mais de $50 \%$ em zona definida como rural pelo IBGE. Grande parte desses municípios apresentam os menores IDH - Índice de Desenvolvimento Humano no Estado de São Paulo e, portanto, altos índices de analfabetismo, mortalidade infantil, nutrição deficiente, condições precárias de habitação, falta de infraestrutura em saneamento básico e insufi-

${ }^{2} \mathrm{O}$ treinamento dos estudantes selecionados ficou a cargo do Prof. Dr. Ulisses Rocha Antuniassi, professor titular na Faculdade de Agronomia da UNESP/ campus de Botucatu, seus estudantes de pós-graduação, juntamente com o Prof. Dr. Luís Carlos Almeida, professor/pesquisador na UNESP/Campus de Registro. Agradecemos a participação dos estudantes Danielle da Silva Gama, Leonardo dos Santos Duarte, Lorenzo Gomes Mascetra e Davenil Augusto Magri. 
ciente oferta de empregos.

Trata-se de uma região de concentração da agricultura familiar que inclui o pequeno produtor rural tradicional, agricultores assentados pela política de reforma agrária, reassentados de barragens e quilombolas. Grande parte desses agricultores se dedica à horticultura, sendo uma das maiores produtoras de tomate do Estado de São Paulo. Algumas cidades como Itapeva, Ribeirão Branco, Guapiara, Capão Bonito, por exemplo, já foram alvo de reportagens de um dos jornais de maior circulação no Estado de São Paulo, tendo em vista as irregularidades constatadas pela fiscalização da DRT e do Ministério Público do Trabalho, que constatou graves problemas na produ-

Mapa 1 - Região do Vale do Ribeira ção e organização do trabalho como não utilização de equipamentos de segurança adequados para o uso de agroquímicos, com o agravante da presença de trabalhadores adolescentes.

Numa primeira fase foram selecionados os seguintes municípios, cujas características se enquadram nos objetivos do projeto.

a) Grupo localizado na região de Itapetininga/Itapeva: Apiaí, Capão Bonito, Itapeva, Ribeirão Branco, São Miguel Arcanjo

b) Municípios do Vale do Ribeira: Cananéia, Eldorado, Jacupiranga, Juquiá, Registro

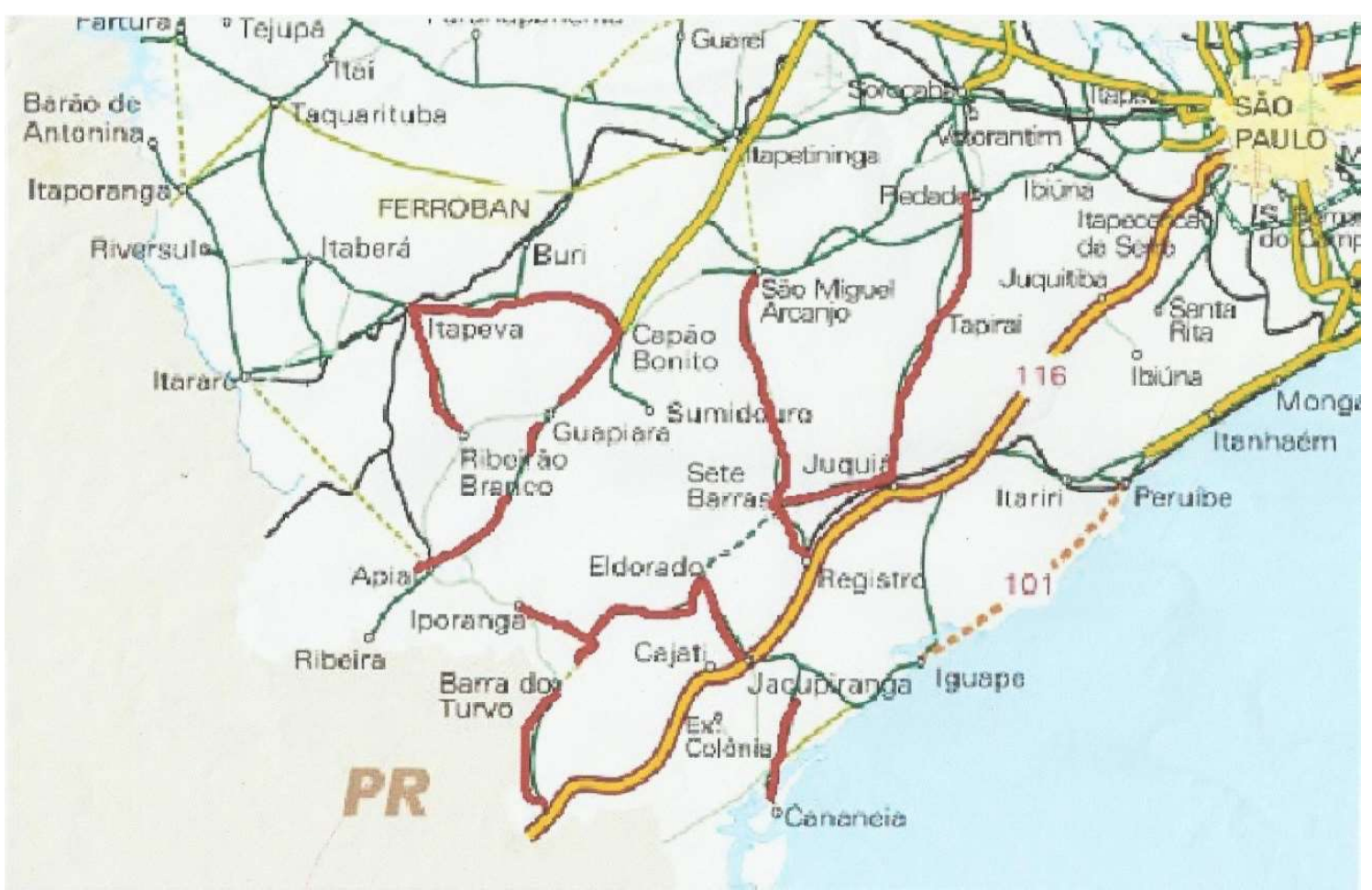

Para a realização do trabalho de campo programado em cada um desses municípios, a equipe entrou em contato com as respectivas Secretarias Municipais de Agricultura, líderes das associações e cooperativas, tendo em vista ter acesso aos produtores rurais da agricultura familiar alvo do treinamento planejado. As cidades nas quais a equipe teve a oportunidade de realizar o projeto após o citado contato, estão abaixo relacionadas com as respectivas datas de realização das atividades planejadas:

\begin{tabular}{|l|c|}
\hline \multicolumn{1}{|c|}{ Cidade } & Data \\
\hline Registro (Sete Barras, Iguape) & $14 / 09 / 2013$ \\
\hline Ribeirão Branco & $21 / 09 / 2013$ \\
\hline Itapeva & $22 / 09 / 2013$ \\
\hline São Miguel Arcanjo ${ }^{1}$ & $05 / 10 / 2013$ \\
\hline Cananéia & $09 / 10 / 2013$ \\
\hline Apiaí & $19 / 10 / 2013$ \\
\hline Guapiara & $20 / 10 / 2013$ \\
\hline Capão Bonito & $25 / 10 / 2013$ \\
\hline Jacupiranga & $01 / 11 / 2013$ \\
\hline Pilar do Sul 1 & $12 / 11 / 2013$ \\
\hline Pilar do Sul 2 & $12 / 12 / 2013$ \\
\hline
\end{tabular}


Caracterização dos Municípios

As palestras ${ }^{3}$ foram realizadas em dez muni cípios pertencentes a quatro Regiões de Governo, que apresentam como característica principal a forte participação da agricultura na economia (Tabela 1).

Tabela 1 - Indicadores socioeconômicos dos Munícipios

\begin{tabular}{|c|c|c|c|c|c|c|}
\hline Município & $\begin{array}{c}\text { População } \\
\text { (2013) }\end{array}$ & $\begin{array}{c}\text { Grau de } \\
\text { urbani- } \\
\text { zação \% } \\
\text { (2010) }\end{array}$ & $\begin{array}{c}\text { Índice Paulista de } \\
\text { Responsabilidade } \\
\text { Social em } \\
2010 \text { (Grupo*) } \\
\text { Responsabilidade } \\
\text { Social em } 2010 \\
(\text { Grupo*) }\end{array}$ & $\begin{array}{c}\text { Partici- } \\
\text { pação dos } \\
\text { Empregos } \\
\text { Formais da } \\
\text { Agricultura } \\
\text { no Total de } \\
\text { Empregos } \\
\text { Formais \% } \\
\text { (2012) }\end{array}$ & $\begin{array}{c}\text { Rendimento } \\
\text { Médio dos } \\
\text { Empregos } \\
\text { Formais da } \\
\text { Agricultura } \\
\text { (Em reais } \\
\text { correntes) } \\
2012\end{array}$ & $\begin{array}{c}\text { Partici- } \\
\text { pação da } \\
\text { Agrope- } \\
\text { cuária no } \\
\text { Total do } \\
\text { Valor Adi- } \\
\text { cionado } \\
\% \text { (2011) }\end{array}$ \\
\hline Estado de São Paulo & - & 95,9 & - & 2,54 & $1.412,49$ & 2,11 \\
\hline \multicolumn{7}{|c|}{ Região de Governo Itapeva } \\
\hline Apiaí & 24.903 & 72,32 & 5 & 8,29 & 768,27 & 11,52 \\
\hline Capão Bonito & 46.153 & 81,91 & 4 & 22,21 & 988,51 & 21,81 \\
\hline Guapiara & 17.818 & 40,19 & 5 & 22,58 & 755,38 & 19,94 \\
\hline Itapeva & 88.823 & 84,28 & 4 & 17,83 & $1.096,28$ & 9,33 \\
\hline Ribeirão Branco & 17.963 & 50,87 & 5 & 54,96 & 763,92 & 14,75 \\
\hline \multicolumn{7}{|c|}{ Região de Governo Registro } \\
\hline Cananéia & 12.217 & 85,36 & 4 & 14,17 & $1.107,13$ & 15,92 \\
\hline Jacupiranga & 17.176 & 54,44 & 4 & 25,87 & 878,12 & 18,69 \\
\hline Registro & 54.107 & 88,77 & 4 & 8,61 & 853,72 & 5,33 \\
\hline \multicolumn{7}{|c|}{ Região de Governo Sorocaba } \\
\hline Pilar do Sul & 26.957 & 78,57 & 3 & 19,09 & $1.140,78$ & 27,82 \\
\hline \multicolumn{7}{|c|}{ Região de Governo Itapetininga } \\
\hline São Miguel Arcanjo & 31.586 & 68,37 & 3 & 34,31 & $1.052,99$ & 39,98 \\
\hline
\end{tabular}

Fonte: Fundação SEADE (2013)

*Grupo 3 - Municípios com nível de riqueza baixo, mas com bons indicadores nas demais dimensões

*Grupo 4 - Municípios que apresentam baixos níveis de riqueza e nível intermediário de longevidade e/ou escolaridade

*Grupo 5 - Municípios mais desfavorecidos, tanto em riqueza quanto nos indicadores sociais

\footnotetext{
${ }^{3}$ No município de São Miguel Arcanjo, embora o trabalho tenha sido planejado com os agrônomos da Secretaria Municipal de Agricultura as atividades de treinamento não foram realizadas tendo em vista condições climáticas desfavoráveis que impediram o deslocamento dos agricultores de seus bairros até o local designado no centro da cidade.
} 
ANTUNIASSI; ALMEIDA. Representação e práticas de utilização de produtos agroquímicos

Conforme se pode observar, todos os municípios apresentam taxa de urbanização inferior à média do Estado (95,9\%), 88,77\% para Registro, com um valor mínimo de 54,4\% para o Município de Jacupiranga.

Um elemento que vem a comprovar a importância da agricultura nesses municípios pode ser aferido tanto pela participação dos empregos formais da agricultura sobre o total dos empregos formais, quanto pela participação do setor agropecuário na própria economia do município.

Se, de um lado, para o Estado de São Paulo, a participação dos empregos formais na agricultura é de $2,54 \%$, verifica-se que esses valores nos municípios trabalhados variam de um mínimo de $8,61 \%$ para o município de Registro chegando a um máximo de $54,96 \%$, da mesma, para os índices da contribuição da agricultura no valor adicionado do município é possível constatar que, se para o Estado de São Paulo esse índice é de 2,11\%, nos municípios trabalhados esse índice, exceto para Registro, praticamente nunca foi inferior a $10 \%$, chegando a um máximo de $39,98 \%$.

Outro ponto que chama a atenção é que, não obstante a forte participação da agricultura na economia, esta não se reflete nos valores dos salários pagos, cujos valores são sistematicamente inferiores aos valores médios do Estado. Um fator que contribui para esse fato está relacionado diretamente ao tipo de agricultura que é praticada nos municípios, que estão voltados basicamente para produtos agrícolas com baixa capacidade de transformação, implicando, portanto, diretamente baixos rendimentos pagos nesse setor, que podem ser assim caracterizadas:

- agricultura de subsistência para o município de Cananéia, bananicultura, região de Governo de Registro;

- olericultura (principalmente o tomate e hortaliças) para os municípios da Região de Governo de Itapeva;
- Cultura da Uva para os municípios de Pilar do Sul e São Miguel Arcanjo.

O ponto comum entre as atividades descritas acima é que são desenvolvidas por pequenos agricultores com utilização, em maior ou menor escala, de agrotóxicos. Dessa forma, constatou-se que, de uma forma ou de outra, todos os agricultores tinham algum conhecimento prévio sobre os riscos que envolvem o uso inadequado dos agrotóxicos.

\section{Pesquisa Aç̃̃o}

\subsection{Estratégias}

No desenvolvimento da pesquisa-ação tendo em vista os objetivos, utilizou-se como estratégias as atividades de palestra, demonstração de utilização de equipamentos e aplicação de um questionário (informação/avaliação). ${ }^{4}$

Tendo em vista avaliar o conhecimento dos participantes e o nível de aprendizado sobre as informações apresentadas pelos pesquisadores, foi realizada uma palestra com demonstração de uso do equipamento de proteção individual (EPI) e de corretas técnicas de utilização dos produtos agroquímicos.

A palestra versou sobre conceitos de intoxicação crônica e aguda, uso, período de aplicação, transporte, armazenamento, destino das embalagens dos produtos agroquímicos usualmente utilizados.

Um questionário foi aplicado em dois momentos distintos: antes do início e ao final da palestra. Por meio do questionário buscou-se obter, a partir das respostas a quinze questões fechadas com respostas do tipo "certo" "errado" e "não sei", o nível de conhecimento e da aprendizagem dos participantes so-

\footnotetext{
${ }^{4}$ Nos intervalos dessas atividades, durante almoços e ou
} lanches procurou-se conversar com os participantes sobre o seu relacionamento com "sua" associação e agrônomos e extensionistas alocados em sua comunidade e região. 
bre os conhecimentos divulgados. Os resultados dos questionários foram tabulados quanto ao número de acertos/erros do respondente, sendo essas informações cruzadas com as variáveis referentes ao local da pesquisa, idade e sexo.

Devido à metodologia utilizada para a análise estatística, foram considerados somente os questionários cujos respondentes participaram das duas fases da pesquisa isto é, palestra e aplicação dos questionários (antes e depois) sendo descartados, portanto, aqueles questionários cujos respondentes participaram somente de uma das fases; também não foram considerados os respondentes da cidade de Registro, onde se realizou o primeiro treinamento e o teste do

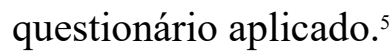

Tabela 2 - Distribuição dos respondentes por cidade

\begin{tabular}{|c|c|c|}
\hline Município & $\begin{array}{c}\text { Frequência } \\
\text { Absoluta }\end{array}$ & $\begin{array}{c}\text { Frequência } \\
\text { Relativa (\%) }\end{array}$ \\
\hline Apiaí & 10 & 8,1 \\
\hline Cananéia & 19 & 15,4 \\
\hline Capão Bonito & 16 & 13,0 \\
\hline Guapiara & 9 & 7,3 \\
\hline Itapeva & 25 & 20,3 \\
\hline Jacupiranga & 10 & 8,1 \\
\hline Pilar do Sul & 27 & 22,0 \\
\hline Ribeirão Branco & 7 & 5,7 \\
\hline Total & 123 & 100,0 \\
\hline
\end{tabular}

\section{Características da população}

Quanto à variável sexo, conforme pode ser visualizado pela tabela 3 , o público participante foi majoritariamente masculino em uma proporção de praticamente 3 para 1.6

\footnotetext{
${ }^{5}$ Em Registro, onde se realizou o primeiro treinamento e o teste do questionário, observou-se que grande parte dos participantes eram jovens agricultores estudantes dos cursos técnicos do município e arredores.
}

${ }^{6}$ Constatou-se, portanto, que em reuniões com as mesmas
Tabela 3 - Sexo dos respondentes

\begin{tabular}{|l|c|c|}
\hline \multicolumn{1}{|c|}{ Sexo } & $\begin{array}{c}\text { Frequência } \\
\text { Absoluta }\end{array}$ & $\begin{array}{c}\text { Frequência } \\
\text { Relativa (\%) }\end{array}$ \\
\hline Masculino & 88 & 72,1 \\
\hline Feminino & 34 & 27,9 \\
\hline Total & 122 & 100,0 \\
\hline
\end{tabular}

Os dados relativos à escolaridade apresentam uma grande dispersão, variando desde apenas um ano de escola formal até nível universitário, com mediana de oito anos de escolaridade. O mesmo fato se observou com a variável idade entre dezoito e oitenta e nove anos, com média igual a 42,6 anos e mediana de 42,5 anos.

Tabela 4 - Resultados de Escolaridade e Idade (anos)

\begin{tabular}{|c|c|c|c|c|c|c|}
\hline $\begin{array}{c}\text { Variá- } \\
\text { vel }\end{array}$ & $\mathrm{N}$ & $\begin{array}{c}\text { Valor } \\
\text { Míni- } \\
\text { mo }\end{array}$ & $\begin{array}{c}\text { Valor } \\
\text { Má- } \\
\text { ximo }\end{array}$ & $\begin{array}{c}\text { Mé- } \\
\text { dia }\end{array}$ & $\begin{array}{c}\text { Me- } \\
\text { dia- } \\
\text { na }\end{array}$ & $\begin{array}{c}\text { Desvio } \\
\text { Padrão }\end{array}$ \\
\hline $\begin{array}{l}\text { Escola- } \\
\text { ridade }\end{array}$ & 111 & 1,00 & 15,00 & 7,6 & 8,0 & 3,99 \\
\hline Idade & 122 & 18,00 & 89,00 & 42,6 & 42,5 & 15,83 \\
\hline
\end{tabular}

\section{REsUlTADOS}

A tabela 5 apresenta os escores de acertos dos questionários respondidos antes da palestra, desdobrada em função de cada questão. características, torna-se necessário reforçar o convite para as mulheres, tendo em vista ampliar a visão da família sobre os prejuízos à saúde dos menores e inclusive o seu impedimento legal. 
Tabela 5 - Escores dos resultados das questões 1 a 15 (Momento antes)

\begin{tabular}{|c|c|c|c|c|c|c|c|c|}
\hline \multirow{2}{*}{ Questões } & \multicolumn{2}{|c|}{ Respostas Erradas } & \multicolumn{2}{|c|}{ Respostas Certas } & \multicolumn{2}{|c|}{ Não Sei } & \multicolumn{2}{|c|}{ Total } \\
\hline & $\mathrm{N}$ & $\%$ & $\mathrm{~N}$ & $\%$ & $\mathrm{~N}$ & $\%$ & $\mathrm{~N}$ & $\%$ \\
\hline $\begin{array}{l}\text { 1) Exposição a uma grande quantidade } \\
\text { de agrotóxicos em curto espaço de tempo } \\
\text { causa intoxicação }\end{array}$ & 33 & 26,8 & 35 & 28,5 & 55 & 44,7 & 123 & 100,0 \\
\hline $\begin{array}{l}\text { 2) Exposição em pequenas quantidades } \\
\text { de agrotoxicos em um longo espaço de } \\
\text { tempo causa intoxicação }\end{array}$ & 28 & 22,8 & 45 & 36,6 & 50 & 40,7 & 123 & 100,0 \\
\hline $\begin{array}{l}\text { 3) Se o aplicador está de luvas, ele pode } \\
\text { fumar entre as aplicações de agrotóxicos }\end{array}$ & 8 & 6,6 & 114 & 93,4 & - & - & 122 & 100,0 \\
\hline $\begin{array}{l}\text { 4) Um agrotóxico "fraco" pode ser peri- } \\
\text { goso mesmo em pequenas quantidades? }\end{array}$ & 4 & 3,3 & 117 & 96,7 & - & - & 121 & 100,0 \\
\hline $\begin{array}{l}\text { 5) Período de carência é o tempo entre a } \\
\text { pulverização e a colheita }\end{array}$ & 39 & 33,3 & 78 & 66,7 & - & - & 117 & 100,0 \\
\hline $\begin{array}{l}\text { 6) Uma área foi pulverizada e o agricul- } \\
\text { tor esqueceu uma ferramenta no meio da } \\
\text { cultura; ele pode entrar para procurar no } \\
\text { final do dia? }\end{array}$ & 39 & 32,8 & 80 & 67,2 & - & - & 119 & 100,0 \\
\hline $\begin{array}{l}\text { 7) Você veio à cidade de caminhonete e } \\
\text { comprou adubos, ração e agrotóxicos, es- } \\
\text { ses produtos podem ir na caçamba? }\end{array}$ & 26 & 21,1 & 97 & 78,9 & - & - & 123 & 100,0 \\
\hline $\begin{array}{l}\text { 8) Você veio à cidade de caminhonete } \\
\text { e comprou adubos, ração e agrotóxicos. } \\
\text { Somente o agrotóxico pode ir na cabine } \\
\text { para não misturar com a ração. }\end{array}$ & 25 & 20,5 & 97 & 79,5 & - & - & 122 & 100,0 \\
\hline $\begin{array}{l}\text { 9) Desde que bem fechado e lacrado, um } \\
\text { agrotóxico pode ser guardado dentro de } \\
\text { casa, desde que o local seja seguro e fe- } \\
\text { chado a chave. }\end{array}$ & 19 & 15,7 & 102 & 84,3 & - & - & 121 & 100,0 \\
\hline $\begin{array}{l}\text { 10) Ao usar o EPI, a bota deve ficar para } \\
\text { fora da calça }\end{array}$ & 75 & 62,5 & 45 & 37,5 & - & - & 120 & 100,0 \\
\hline $\begin{array}{l}\text { 11) Ao pulverizar uma cultura com a mão } \\
\text { para cima a luva tem que ficar }\end{array}$ & 30 & 24,8 & 91 & 75,2 & - & - & 121 & 100,0 \\
\hline $\begin{array}{l}\text { 12) Ao pulverizar uma cultura com a mão } \\
\text { para baixo a luva tem que ficar }\end{array}$ & 47 & 39,2 & 73 & 60,8 & - & - & 120 & 100,0 \\
\hline $\begin{array}{l}\text { 13) As embalagens vazias de agrotóxicos, } \\
\text { para evitar contaminação, devem ser en- } \\
\text { terradas em um local seguro }\end{array}$ & 42 & 35,0 & 78 & 65,0 & - & - & 120 & 100,0 \\
\hline $\begin{array}{l}\text { 14) Na hora de aplicar o agrotóxico, o } \\
\text { aplicador deve ficar }\end{array}$ & 51 & 42,5 & 69 & 57,5 & - & - & 120 & 100,0 \\
\hline $\begin{array}{l}\text { 15) Dias quentes e bem secos são bons } \\
\text { para aplicar o agrotóxico }\end{array}$ & 32 & 26,7 & 88 & 73,3 & - & - & 120 & 100,0 \\
\hline
\end{tabular}

Tomando-se como critério, para os erros, que uma porcentagem de erro superior a $30 \%$ denota uma situação no qual o nível de informação prévio é insuficiente, podemos verificar que tal situação ocorreu em seis das questões: $10,14,12,13,5$ e 6 . Essas questões estão intimamente relacionadas ao uso do EPI
(10 e 12), técnica de aplicação (14), destino das embalagens (13) e período de carência (5) e reentrada na área pulverizada (6).

Por sua vez, tendo como base um acerto mínimo de $80 \%$, verificou-se que as informações referentes ao armazenamento, ao fato de não se poder fumar 
entre as aplicações, e um agrotóxico "fraco", pode ser perigoso, mesmo em pequenas quantidades.

Quanto às questões 1 e 2 , que tratam de pontos referentes à intoxicação, não menos que $40 \%$ dos respondentes não souberam diferenciar intoxicação aguda da intoxicação crônica, com acertos da ordem de $27,5 \%$ e $36,6 \%$, respectivamente.

Os dados da tabela 6 apresentam uma distribuição das frequências de acertos por questionário no momento ANTES.

Tabela 6 - Número total de acertos por questionários (momento antes)

\begin{tabular}{|l|r|r|}
\hline Número de acertos & \multicolumn{1}{|c|}{$\begin{array}{l}\text { Frequência } \\
\text { absoluta }\end{array}$} & \multicolumn{1}{c|}{$\begin{array}{c}\text { Frequência } \\
\text { relativa (\%) }\end{array}$} \\
\hline Três & 1 &, 8 \\
\hline Seis & 7 & 5,7 \\
\hline Sete & 14 & 11,4 \\
\hline Oito & 17 & 13,8 \\
\hline Nove & 26 & 21,1 \\
\hline Dez & 30 & 24,4 \\
\hline Onze & 20 & 16,3 \\
\hline Doze 0 & 8 & 6,5 \\
\hline Total & 123 & 100,0 \\
\hline
\end{tabular}

Verifica-se, ainda, que nas informações contidas nos questionários sobre as questões básicas da utilização de agrotóxicos, nenhum dos respondentes acertou todas as questões, o que pode ser um indicador de que nem todas as informações sobre o uso correto de agrotóxicos estão disseminadas ou, se estão, esses conceitos não se fixaram entre a população.

Os resultados para cada questão, em termos do número de acertos, estão sintetizados na tabela 7 , a seguir: 
Tabela 7 - Escores dos resultados das questões 1 a 15 (Momento depois)

\begin{tabular}{|c|c|c|c|c|c|c|c|c|}
\hline \multirow{2}{*}{ Questões } & \multicolumn{2}{|c|}{ Respostas Erradas } & \multicolumn{2}{|c|}{ Respostas Certas } & \multicolumn{2}{|c|}{ Não Sei } & \multicolumn{2}{|c|}{ Total } \\
\hline & $\mathbf{N}$ & $\%$ & $\mathbf{N}$ & $\%$ & $\mathbf{N}$ & $\%$ & $\mathbf{N}$ & $\%$ \\
\hline $\begin{array}{l}\text { 1) Exposição a uma grande quanti- } \\
\text { dade de agrotóxicos em curto espa- } \\
\text { ço de tempo causa intoxicação }\end{array}$ & 19 & 15,4 & 98 & 79,7 & 6 & 4,9 & 123 & 100,0 \\
\hline $\begin{array}{l}\text { 2) Exposição em pequenas quanti- } \\
\text { dades de agrotóxicos em um longo } \\
\text { espaço de tempo causa intoxicação }\end{array}$ & 15 & 12,2 & 101 & 82,1 & 7 & 5,7 & 123 & 100,0 \\
\hline $\begin{array}{l}\text { 3) Se o aplicador está de luvas, ele } \\
\text { pode fumar entre as aplicações de } \\
\text { agrotóxicos }\end{array}$ & 1 & 0,8 & 122 & 99,2 & - & - & 123 & 100,0 \\
\hline $\begin{array}{l}\text { 4) Um agrotóxico "fraco" pode } \\
\text { ser perigoso, mesmo em pequenas } \\
\text { quantidades? }\end{array}$ & 5 & 4,1 & 118 & 95,9 & - & - & 123 & 100,0 \\
\hline $\begin{array}{l}\text { 5) Período de carência é o tempo } \\
\text { entre a pulverização e a colheita }\end{array}$ & 25 & 20,7 & 96 & 79,3 & - & - & 121 & 100,0 \\
\hline $\begin{array}{l}\text { 6) Uma área foi pulverizada e o } \\
\text { agricultor esqueceu uma ferramenta } \\
\text { no meio da cultura; ele pode entrar } \\
\text { para procurar no final do dia? }\end{array}$ & 10 & 8,4 & 109 & 91,6 & - & - & 119 & 100,0 \\
\hline $\begin{array}{l}\text { 7) Você veio à cidade de caminho- } \\
\text { nete e comprou adubos, ração e } \\
\text { agrotóxicos, esses produtos podem } \\
\text { ir na caçamba? }\end{array}$ & 24 & 19,5 & 99 & 80,5 & - & - & 123 & 100,0 \\
\hline $\begin{array}{l}\text { 8) Você veio à cidade de caminho- } \\
\text { nete e comprou adubos, ração e } \\
\text { agrotóxicos. Somente o agrotóxico } \\
\text { pode ir na cabine para não misturar } \\
\text { com a ração. }\end{array}$ & 10 & 8,2 & 112 & 91,8 & - & - & 122 & 100,0 \\
\hline $\begin{array}{l}\text { 9) Desde que bem fechado e lacra- } \\
\text { do, um agrotóxico pode ser guarda- } \\
\text { do dentro de casa, desde que o local } \\
\text { seja seguro e fechado a chave. }\end{array}$ & 8 & 6,6 & 114 & 93,4 & - & - & 122 & 100,0 \\
\hline $\begin{array}{l}\text { 10) Ao usar o EPI, a bota deve ficar } \\
\text { para fora da calça }\end{array}$ & 87 & 71,3 & 35 & 28,7 & - & - & 122 & 100,0 \\
\hline $\begin{array}{l}\text { 11) Ao pulverizar uma cultura com } \\
\text { a mão para cima a luva tem que fi- } \\
\text { car }\end{array}$ & 20 & 16,7 & 100 & 83,3 & - & - & 120 & 100,0 \\
\hline $\begin{array}{l}\text { 12) Ao pulverizar uma cultura com } \\
\text { a mão para baixo a luva tem que fi- } \\
\text { car }\end{array}$ & 17 & 14,3 & 102 & 85,7 & - & - & 119 & 100,0 \\
\hline $\begin{array}{l}\text { 13) As embalagens vazias de agro- } \\
\text { tóxicos, para evitar contaminação, } \\
\text { devem ser enterradas em um local } \\
\text { seguro }\end{array}$ & 20 & 16,3 & 103 & 83,7 & - & - & 123 & 100,0 \\
\hline $\begin{array}{l}\text { 14) Na hora de aplicar o agrotóxico } \\
\text { o aplicador deve ficar }\end{array}$ & 31 & 25,4 & 91 & 74,6 & - & - & 122 & 100,0 \\
\hline $\begin{array}{l}\text { 15) Dias quentes e bem secos são } \\
\text { bons para aplicar o agrotóxico }\end{array}$ & 15 & 12,3 & 107 & 87,7 & - & - & 122 & 100,0 \\
\hline
\end{tabular}


No momento DEPOIS, ocorre uma sensível redução da porcentagem de questões com resultados errados, não existindo, nesse momento, nenhuma questão com índice de erro superior a 30\%. Por sua vez, à exceção das questões 10 e 14, praticamente todas as demais apresentaram índice de acerto superior (ou próximo disso) a 80\%, devendo ser destacada uma sensível redução dos níveis de erro bem como da alternativa "não sei" para as questões 1 e 2 , o que demonstra que a didática apresentada contribuiu para o aprendizado dos respondentes, conforme pode ser verificado pelo aumento do número de acertos.

Tabela 8 - Número total de acertos por questionários (momento depois)

\begin{tabular}{lcc}
\hline Número de acertos & $\begin{array}{c}\text { Frequência } \\
\text { absoluta }\end{array}$ & $\begin{array}{c}\text { Frequência } \\
\text { relativa (\%) }\end{array}$ \\
\hline Cinco & 1 & 0,8 \\
Seis & 1 & 0,8 \\
Sete & 4 & 3,3 \\
Oito & 12 & 9,8 \\
Nove & 11 & 8,9 \\
Dez & 18 & 14,6 \\
Onze & 23 & 18,7 \\
Doze & 48 & 39,0 \\
Treze & 5 & 4,1 \\
\hline Total & 123 & 100,0 \\
\hline
\end{tabular}

Quanto ao acerto total, entre os momentos ANTES e DEPOIS ocorre uma significativa mudança no total de acertos. Se, no momento ANTES, apenas vinte e oito pessoas acertaram onze ou mais questões, no momento DEPOIS esse valor sobe a setenta e seis.

Para verificar a existência de possíveis relações entre acertos e erros análises estatísticas mais específicas foram realizadas. Para tanto os resultados foram cruzados com as variáveis idade, sexo, escolaridade e local de palestra. Da mesma forma foram realizados testes para comprovar a hipótese de que as diferenças observadas entre os dois momentos apre- sentaram significância estatística tanto para o total dos acertos, quanto para as questões individuais.

A tabela 9, a seguir, mostra os resultados das correlações de Pearson para as variáveis, Idade, Anos de Escolaridade e Total de acertos para os dois momentos.

Tabela 9 - Correlação do número de acertos com as variáveis Idade e Escolaridade

\begin{tabular}{|l|l|c|c|c|}
\hline \multirow{2}{*}{$\begin{array}{c}\text { Variá- } \\
\text { vel }\end{array}$} & Estatística & Idade & $\begin{array}{c}\text { Total de } \\
\text { ques- } \\
\text { tões } \\
\text { certas }- \\
\text { antes }\end{array}$ & $\begin{array}{c}\text { Total de } \\
\text { questões } \\
\text { certas - } \\
\text { depois }\end{array}$ \\
\hline \multirow{2}{*}{ Idade } & $\begin{array}{c}\text { Correlação } \\
\text { de Pearson }\end{array}$ & - & $-0,052$ & $-0,211$ \\
\cline { 2 - 3 } \cline { 4 - 5 } Escola- \\
ridade & $\begin{array}{l}\text { Correlação } \\
\text { de Pearson }\end{array}$ & $-0,435$ & 0,165 & 0,201 \\
\cline { 2 - 5 } & (p-valor) & $<$ & 0,083 & 0,035 \\
\hline
\end{tabular}

Inicialmente os resultados mostram a existência de correlação inversa entre Idade e Escolaridade ( $\mathrm{r}=$ $-0,435)$ isto é, quanto mais velho o respondente, menos anos de escolaridade este tinha e vice-versa.

Interessante observar que não houve correlação significativa do total de acertos no momento ANTES, tanto para idade quanto para escolaridade. No segundo momento, DEPOIS, os coeficientes de correlação foram significativos para as duas variáveis no sentido inverso. Para Idade, o valor de Pearson negativo significa que, quanto maior a idade menor o número de acertos, no entanto, para Escolaridade, o sinal negativo do coeficiente de correlação indica que, quanto maior a escolaridade menor o número de acertos, fato esse que certamente deve merecer uma análise mais aprofundada. Pode-se levantar a hipótese de que sejam participantes mais distantes das atividades agrícolas, por exemplo, pessoal administrativo 
84 ANTUNIASSI; ALMEIDA. Representação e práticas de utilização de produtos agroquímicos ... das prefeituras e cooperativas.

As tabelas 10 e 11 mostram o total de acertos para os dois momentos, antes e depois, tendo como variável de recorte o sexo.

Tabela 10 - Total de questões certas, momento antes dividida por sexo do respondente

\begin{tabular}{|c|c|c|c|c|c|c|c|c|c|}
\hline \multirow{2}{*}{ Sexo } & \multicolumn{8}{|c|}{ Total de questões certas - antes } & \multirow{2}{*}{ Total } \\
\hline & Três & Seis & Sete & Oito & Nove & Dez & Onze & Doze & \\
\hline Masculino & 1 & 6 & 9 & 12 & 18 & 20 & 16 & 6 & 88 \\
\hline Feminino & 0 & 1 & 4 & 5 & 8 & 10 & 4 & 2 & 34 \\
\hline Total & 1 & 7 & 13 & 17 & 26 & 30 & 20 & 8 & 122 \\
\hline
\end{tabular}

p-valor 0,953, Qui-quadrado pelo método de Monte Carlo

Tabela 11 - Total de questões certas, momento depois dividida por sexo do respondente.

\begin{tabular}{|c|c|c|c|c|c|c|c|c|c|c|}
\hline \multirow{2}{*}{ Sexo } & \multicolumn{9}{|c|}{ Total de questões certas - depois } & \multirow{2}{*}{ Total } \\
\hline & Cinco & Seis & Sete & Oito & Nove & Dez & Onze & Doze & Treze & \\
\hline Masculino & 1 & 1 & 3 & 10 & 8 & 12 & 15 & 35 & 3 & 88 \\
\hline Feminino & 0 & 0 & 1 & 2 & 3 & 5 & 8 & 13 & 2 & 34 \\
\hline Total & 1 & 1 & 4 & 12 & 11 & 17 & 23 & 48 & 5 & 122 \\
\hline
\end{tabular}

p-valor 0,977, Qui-quadrado pelo método de Monte Carlo

Os dados mostram que a variável sexo não e que a melhora dos resultados se deu de forma homoteve qualquer relação com o número de acertos, tanto gênea entre estes. no momento ANTES quanto no momento DEPOIS, o que permite concluir que o grau de conhecimento no momento ANTES era igual entre homens e mulheres

A análise dos acertos dos respondentes, em função das cidades, está descrita na tabela 12 a seguir:

Tabela 12 - Média dos acertos dos respondentes, por cidade, momentos ANTES e DEPOIS

\begin{tabular}{|c|c|c|c|c|c|c|c|}
\hline \multirow[b]{2}{*}{ Cidade } & \multirow[b]{2}{*}{$\mathbf{N}$} & \multicolumn{2}{|c|}{ Momento Antes } & \multicolumn{2}{|c|}{ Momento Depois } & \multirow{2}{*}{$\begin{array}{c}\text { Diferença ab- } \\
\text { soluta }\end{array}$} & \multirow[b]{2}{*}{ p-valor(*) } \\
\hline & & Média & $\begin{array}{c}\text { Desvio Pa- } \\
\text { drão }\end{array}$ & Média & $\begin{array}{c}\text { Desvio Pa- } \\
\text { drão }\end{array}$ & & \\
\hline Itapeva & 25 & 8,72 & 1,57 & 10,52 & 1,73 & 1,80 & 0,000 \\
\hline Ribeirão Branco & 7 & 9,57 & 0,98 & 10,57 & 1,51 & 1,00 & 0,062 \\
\hline Pilar do Sul & 27 & 10,04 & 1,45 & 10,93 & 1,41 & 0,89 & 0,035 \\
\hline Cananéia & 17 & 8,00 & 1,97 & 10,71 & 1,72 & 2,71 & 0,001 \\
\hline Apiaí & 10 & 9,30 & 1,34 & 9,80 & 2,25 & 0,50 & 0,475 \\
\hline Guapiara & 9 & 9,33 & 1,58 & 11,44 & 0,73 & 2,11 & 0,007 \\
\hline Capão Bonito & 16 & 9,50 & 1,83 & 10,50 & 1,83 & 1,00 & 0,072 \\
\hline Jacupiranga & 10 & 9,20 & 1,48 & 10,40 & 2,12 & 1,20 & 0,024 \\
\hline
\end{tabular}

(*) valores do teste t para dados emparelhados 
Como pode ser observado, das sete cidades onde foram aplicados os questionários, em três delas não ocorreram diferenças estatisticamente significativas entre os dois momentos (ANTES e DEPOIS), Ribeirão Branco, Apiaí e Capão Bonito sendo, para as demais cidades, todas as diferenças significativas.

Para o primeiro momento, uma análise de variância tomando como variável base as médias de cada cidade mostraram diferenças entre elas, sendo possível determinar pelo teste de Tukey que as diferenças significativas $(\mathrm{p}=0,008)$ eram observadas somente entre as cidades Cananéia (média de 8,00 acertos) e Pilar do Sul (com média de acertos de 10,04).
Por sua vez, a mesma análise de variância realizada para as médias de acertos entre as cidades operada no segundo momento não mostrou diferenças significativas entre elas $(p=0,576)$, o que implica dizer que, se alguma diferença existia entre as cidades no primeiro momento (ANTES), estas deixaram de existir no segundo momento (DEPOIS).

A tabela 13, a seguir mostra os resultados das análises de qui-quadrado para as questões 1 e 2 que, dada a complexidade do tema, foi codificada de três formas diferentes, respostas "errada", "certa" e "não sei”.

Tabela 13 - Resultados das questões 1 e 2, momentos ANTES e momento DEPOIS

\begin{tabular}{|l|c|c|c|c|c|}
\hline \multicolumn{1}{|c|}{ Questões } & Resultados & Antes & Depois & Total & \multirow{2}{*}{ p-valor } \\
\hline \multirow{2}{*}{$\begin{array}{l}\text { 1) Exposição a uma grande quantidade de } \\
\text { agrotóxicos em curto espaço de tempo cau- } \\
\text { sa intoxicação }\end{array}$} & Erradas & 33 & 19 & 52 & \multirow{2}{*}{$<0,0001$} \\
\cline { 2 - 5 } & Certas & 35 & 98 & 133 & \\
\cline { 2 - 5 } Total & Não Sei & 55 & 6 & 61 & \\
\hline & & 123 & 123 & 246 & \\
\hline \multirow{2}{*}{$\begin{array}{l}\text { 2) Exposição em pequenas quantidades de } \\
\text { agrotóxicos em um longo de tempo causa } \\
\text { intoxicação }\end{array}$} & Erradas & 25 & 15 & 40 & \multirow{2}{*}{$<0,0001$} \\
\cline { 2 - 5 } & Certas & 45 & 101 & 146 & \\
\cline { 2 - 5 } Total & Não Sei & 53 & 7 & 57 & \\
\hline
\end{tabular}

As diferenças observadas entre os dois momentos apresentaram significância estatística, pelo teste de qui-quadrado, da ordem de $\mathrm{p}<0.0001$, o que indica que as reduções das respostas "erradas" e "não sei" e aumento das respostas "certas", entre os dois momentos, foi altamente significativa.

A tabela 14, abaixo, mostra para o conjunto de todos os respondentes o número médio de acertos entre os momentos antes e depois para as questões de 3 a 15. 
Tabela 14 - Média de acertos por questão nos momentos ANTES de DEPOIS

\begin{tabular}{|c|c|c|c|c|c|c|}
\hline \multirow[b]{2}{*}{ Pergunta } & \multirow[b]{2}{*}{$\mathbf{N}$} & \multicolumn{2}{|c|}{ Momento Antes } & \multicolumn{2}{|c|}{ Momento De'pois } & \multirow{2}{*}{$\begin{array}{c}\text { p-valor } \\
(*)\end{array}$} \\
\hline & & Média & $\begin{array}{l}\text { Desvio Pa- } \\
\text { drão }\end{array}$ & Média & $\begin{array}{l}\text { Desvio } \\
\text { Padrão }\end{array}$ & \\
\hline $\begin{array}{l}\text { 3) Se o aplicador está de luvas, ele pode } \\
\text { fumar entre as aplicações de agrotóxicos }\end{array}$ & 122 & 0,93 & 0,25 & 0,99 & 0,09 & 0,02 \\
\hline $\begin{array}{l}\text { 4) Um agrotóxico "fraco" pode ser perigo- } \\
\text { so, mesmo em pequenas quantidades? }\end{array}$ & 121 & 0,97 & 0,18 & 0,96 & 0,20 & 0,71 \\
\hline $\begin{array}{l}\text { 5) Período de carência é o tempo entre a } \\
\text { pulverização e a colheita }\end{array}$ & 116 & 0,67 & 0,47 & 0,79 & 0,41 & 0,02 \\
\hline $\begin{array}{l}\text { 6) Uma área foi pulverizada e o agricultor } \\
\text { esqueceu uma ferramenta? }\end{array}$ & 116 & 0,68 & 0,47 & 0,91 & 0,28 & $<0,000$ \\
\hline $\begin{array}{l}\text { 7) Comprou adubos, ração e agrotóxicos, } \\
\text { esses produtos podem ir na caçamba? }\end{array}$ & 123 & 0,79 & 0,41 & 0,80 & 0,40 & 0,72 \\
\hline $\begin{array}{l}\text { 8) Somente o agrotóxico pode ir na cabine } \\
\text { para não misturar com a ração. }\end{array}$ & 121 & 0,79 & 0,41 & 0,92 & 0,28 & $<0,00$ \\
\hline $\begin{array}{l}\text { 9) Desde que bem fechado e lacrado pode } \\
\text { ser guardado dentro de casa, }\end{array}$ & 120 & 0,84 & 0,37 & 0,93 & 0,25 & 0,03 \\
\hline $\begin{array}{l}\text { 10) Ao usar o EPI a bota deve ficar para } \\
\text { fora da calça }\end{array}$ & 119 & 0,37 & 0,48 & 0,29 & 0,45 & 0,14 \\
\hline $\begin{array}{l}\text { 11) Ao pulverizar uma cultura com a mão } \\
\text { para cima, a luva tem que ficar }\end{array}$ & 118 & 0,75 & 0,43 & 0,84 & 0,37 & 0,11 \\
\hline $\begin{array}{l}\text { 12) Ao pulverizar uma cultura com a mão } \\
\text { para baixo, a luva tem que ficar }\end{array}$ & 116 & 0,62 & 0,49 & 0,85 & 0,36 & $<0,00$ \\
\hline $\begin{array}{l}\text { 13) As embalagens vazias de agrotóxicos, } \\
\text { devem ser enterradas em um local seguro }\end{array}$ & 120 & 0,65 & 0,48 & 0,83 & 0,37424 & $<0,00$ \\
\hline $\begin{array}{l}\text { 14) Na hora de aplicar o agrotóxico o apli- } \\
\text { cador deve ficar }\end{array}$ & 119 & 0,57 & 0,50 & 0,75 & 0,43605 & $<0,01$ \\
\hline $\begin{array}{l}\text { 15) Dias quentes e bem secos são bons } \\
\text { para aplicar o agrotóxico }\end{array}$ & 119 & 0,74 & 0,44 & 0,87 & 0,33331 & $<0,01$ \\
\hline Total de questões certas & 123 & 9,18 & 1,69 & 10,63 & 1,69 & $<0.00$ \\
\hline
\end{tabular}

(*) valores do teste t para dados emparelhados

Como pode ser observado, para as questões 4, 7, $10 \mathrm{e}$ 11 não houve diferença da média de acertos entre os dois momentos. Cabe destacar que, para a questão 4, a média de acertos já era alta no primeiro momento, pouco contribuindo a palestra para uma mudança de opinião. Por sua vez, a manutenção do nível de acertos entre os dois momentos mostra que, não obstante a parte prática ter enfatizado a posição da bota em relação ao EPI, bem como a posição da mão no momento da aplicação, que certos hábitos estão de tal forma enraizados que mais ações, principalmente sobre o uso correto do EPI, devem ser realizadas. Da mesma fora, o transporte de agrotóxicos, mesmo na caçamba da caminhonete, junto com outros produtos é um hábito difícil de ser alterado.

Finalmente, a diferença das médias para todas as questões entre os dois momentos (ANTES e DEPOIS) de 9,18 acertos, no primeiro momento, para 10,63 acertos apresentou diferença significativa com valor de $\mathrm{p}<0,001$, isto é, estatisticamente o nível de acerto melhorou após a apresentação das palestras.

Observou-se, portanto, que os resultados são bastante positivos e embora se tenha observado que os agricultores conhecem uma parte das questões propostas na pesquisa, o conjunto das normas de segurança na utilização de agroquímicos ainda é desconhecido de significativo percentual da população, 
sobretudo o rigor na utilização do EPI, armazenamento e período de carência da aplicação, assim como pontos relativos à diferenciação entre intoxicação aguda e crônica.

\section{CONSIDERAÇÕES FINAIS}

Num primeiro momento foi pensado organizar os treinamentos nos finais de semana (sábados e domingos) com a possibilidade de que, em uma só viagem, fosse possível realizar atividades em dois municípios próximos. Entretanto, logo nos primeiros contatos verificou-se a impossibilidade de obter a anuência dos municípios nas datas previstas. Passou-se, então, a programar as atividades em dez municípios, em dias de semana, tendo em vista atingir um número satisfatório de agricultores participantes.?

Para ter acesso aos agricultores de cada município, foram contatados os engenheiros agrônomos das respectivas secretarias municipais de agricultura e meio ambiente. Partiu-se do pressuposto que esta seria a melhor abordagem para ter acesso aos agricultores das associações e cooperativas de produtores rurais.

Entretanto, constatou-se que, nesse momento histórico, tendo em vista significativas alterações no contexto da Extensão Rural no Estado de São Paulo, com a municipalização das ações de extensão ru$\mathrm{ral}^{8}$, pode ter havido uma retração da ação direta dos

7 Conforme dados em anexo, foi planejado atingir uma população de 400 agricultores, com grande esforço da equipe, e replanejamento conseguiu-se atingir cerca de $70 \%$ da população prevista.

8 Existem pesquisas mostrando que ao lado dos bons resultados da municipalização das ações de extensão rural observa-se um efeito negativo no sentido de que há, em grande parte dos municípios paulistas, uma rotatividade muito grande entre técnicos agrícolas e engenheiros agrônomos extensionistas, devido aos baixos salários oferecidos pelas prefeituras.

ANTUNIASSI, M. H. R. Evolução do processo de formação, organização e atuação das associações de pequenos produtores rurais: Programa Estadual de Microbacias Hidrográficas. Campinas: CATI, 2009. 101 p. il. (Impresso Especial CATI). engenheiros agrônomos da CATI (Coordenadoria da Assistência Técnica Integral) - Secretaria de Agricultura, o que possibilita levantar a hipótese de que o associativismo no Estado de São Paulo em determinadas regiões, de certa forma, arrefeceu e o contato de técnicos e agrônomos extensionistas com os agricultores tornou-se menos frequente e provavelmente menos efetivo. Assim sendo, a estratégia de contato primeiro com as secretarias municipais não surtiu o efeito esperado, à medida que se obteve um comparecimento de aproximadamente $50 \%$ da população convidada pelas secretarias municipais. ${ }^{9}$

Acredita-se que, num próximo projeto de atividades com o mesmo público, seria mais produtivo o contato direto com as lideranças das associações e cooperativas, tendo em vista a realização dos treinamentos nos próprios bairros rurais de habitação dos agricultores. De fato, entre os onze treinamentos realizados, a maior participação foi no município de Itapeva, onde o mesmo foi realizado no âmbito de um bairro rural - Quilombo do Jaó e em Itapeva. Uma importante observação, que pede aprofundamento da pesquisa, é o distanciamento observado dos agricultores de suas cooperativas, e o pequeno entrosamento com os agrônomos de suas comunidades. No estudo acima citado, sobre a "Evolução do processo de formação, organização e atuação das associações de pequenos produtores rurais - Programa Estadual de Microbacias Hidrográficas" foi possível verificar que a estabilidade e o sucesso das associações estão fortemente ligados à capacidade de gerenciar e criar recursos e a presença constante do agrônomo extensionista é fator fundamental no desenvolvimento dessas atividades (ANTUNIASSI, 2009 p. 62).

Fazemos compras em conjunto, as palestras são organizadas pela associação. Nas reuniões a gente organiza as palestras, como a de Aplicação de Defensivos e Uso de EPI (equipamento de proteção

9 Nesse caso, o período de atividades anterior à efetivação do treinamento deveria ser estendido, tendo em vista maior número de viagens para contato prévio com a população alvo. 
individual)". Trecho de entrevista (APR do Sitio dos Campos) (ANTUNIASSI, op.cit, p.62).

A reunião é realizada na casa dos associados, estamos entrando em contato com a prefeitura para ocuparmos uma escola desativada, os associados vão se encarregar da reforma" (entrevista com o agrônomo). (ANTUNIASSI, op cit.,, 2009 , p. 54.

Nesse caso, constata-se que se torna necessário um estreitamento das relações entre agrônomos e técnicos extensionistas com os pequenos agricultores familiares e suas associações para que as mesmas sejam revitalizadas e cumpram o seu papel no desenvolvimento agrícola, sobretudo no que se refere ao papel da agricultura familiar, predominante na região em questão. Finalizando, pode-se dizer que o trabalho pedagógico e de observação sociológica permitiu o levantamento de uma série de dados e de hipóteses explicativas a serem retomadas em futuros estudos e, portanto, que a metodologia pesquisa-ação e respectivas estratégias utilizadas responderam satisfatoriamente, permitindo a obtenção dos resultados esperados.

REFERÊNCIAS BIBLIOGRÁFICAS

ANADÓN, Marta (sous la direction) La recherche participative: Multiples Regards. Presses de 1'Université du Quebec, 2008.

ANTUNIASSI, Maria Helena Rocha. Evolução do processo de formação, organização e atuação das associações de pequenos produtores rurais Impresso Especial CATI: Campinas, 2009.

BOURDIEU, Pierre. L'objectivation participante. Actes de la recherche en sciences sociales. Paris, p. 4358. http://www.cairn.info/revue-actes-de-la-recherche-en-sciences-sociales-2003-5-page-43.htm.

JAS, Nathalie, Pesticides et santé des travailleurs agricoles en France Questions anciennes, nouveaux enjeux, Courrier de l'environnement de l'INRA $\mathrm{n}^{\circ} 59$, oct. 2010.

LAPASSADE, Georges (Synthèse remaniée par Hugues Bazin à partir de deux versions d'un texte (dactylographié et publié) de George LAPASSADE, 1991-1993 «De l'ethnographie de l'école à la nouvelle recherche-action», Université de Paris VIII. (file://I:/Recherche\%20Action\%20Par\%20Georges\%20Lapassade.htm)

LAPORTE, Christian Gonzalez. Recherche-action participative, collaborative, intervention, Quelles explicitations (http://hal.univ-grenoble-alpes.fr/hal01022115)

TRIPP, David. Pesquisa-ação: uma introdução metodológica. Educação e Pesquisa, São Paulo, v. 31, n. 3, p. 443-466, set./dez. 2005.

SOULÉ BASTIEN, Observation participante ou participation observante? Usages et justifications de la notion de participation observante en sciences sociales. Soulé Bastien, Ph.D. Université de Caen Basse-Normandie. 


\section{Anexo 1}

Questionário - 2.a Fase

Idade anos Sexo:

( ) Homem

( ) Mulher Última série que você estudou

1) Exposição a uma grande quantidade de agrotóxicos em curto espaço de tempo causa uma intoxicação

2) Exposição em pequenas quantidades de agrotóxicos em um longo de tempo causa uma intoxicação

3) Se o aplicador está de luvas ele pode fumar entre as aplicações de agrotóxicos

4) Um agrotóxico "fraco" pode ser perigoso mesmo em pequenas quantidades?

5) Período de carência é o tempo entre a pulverização e a colheita

6) Uma área foi pulverizada e o agricultor esqueceu uma ferramenta no meio da cultura ele pode entrar para procurar no final do dia?

7) Você veio na cidade de caminhonete e comprou adubos, ração e agrotóxicos, esses produtos podem ir na caçamba?

( ) Aguda ( ) Crônica ( ) Não sei

( ) Aguda ( ) Crônica ( ) Não sei

( ) $\operatorname{Sim} \quad$ ( ) Não

( ) $\operatorname{Sim} \quad$ ( ) Não

( ) Certo ( ) Errado

( ) Sim ( ) Não

8) Você veio na cidade de caminhonete e comprou adubos, ração e agrotóxicos. Somente o agrotóxico pode ir na cabine para não misturar com a ração.

9) Desde que bem fechado e lacrado um agrotóxico pode ser guardado dentro de casa, desde que o local seja seguro ( ) Certo ( ) Errado e fechado a chave.

10) Ao usar o EPI a bota deve ficar para fora da calça

11) Ao pulverizar uma cultura com a mão para cima a luva tem que ficar

12) Ao pulverizar uma cultura com a mão para baixo a luva tem que ficar

13) As embalagens vazias de agrotóxicos, para evitar contaminação, devem ser enterradas em um local seguro

14) na hora de aplicar o agrotóxico o aplicador deve ficar

15) Dias quentes e bem secos são bons para aplicar o agrotóxico

( ) Certo ( ) Errado

( ) por cima do macacão

( ) por baixo do macacão

( ) por cima do macacão

( ) por baixo do macacão

( ) Certo ( ) Errado

( ) a favor do vento $(\underset{\text { vento }}{\text { ) contra o }}$

( ) Certo ( ) Errado 